\title{
STRUCTURAL CHANGES IN FOOT AND ARCH DIMENSIONS IN THE THIRD TRIMESTER OF PREGNANCY
}

original paper

( ) University School of Physical Education in Wroclaw

DOI: https://doi.org/10.5114/hm.2021.100017

\section{KATARZYNA BARCZYK-PAWELEC, ARLETTA HAWRYLAK, ADRIAN BIŃCZYK, EWA DEMCZUK-WEODARCZYK}

Faculty of Physiotherapy, University School of Physical Education in Wrocław, Wrocław, Poland

\begin{abstract}
Purpose. The goal of the study was to investigate changes in foot anatomical characteristics in the last trimester of pregnancy. Methods. Twenty pregnant women (mean age: 30.8 years) from a local clinic were recruited. Body mass, foot length and width, longitudinal arch height, and several angular variables quantifying plantar and arch structure were measured. A foot imprint was obtained with a digital podoscope (CQ Elektronik System, Poland) at the beginning and end of the third trimester of pregnancy.

Results. Body mass was significantly greater at the end of the last trimester. Increases were also observed in the SztriterGodunow index in both feet $(p<0.007)$, although foot length and width increased only in the left foot. Among the angular characteristics, the only significant changes involved an increase in the talocalcaneal angle $(p<0.007)$ and a decrease in the $1^{\text {st }}$ metatarsophalangeal angle in the right foot $(p<0.04)$.

Conclusions. Significant changes in plantar and arch structure were observed in the final trimester of pregnancy, primarily involving a transverse expansion of the left foot and alteration in the angular characteristics of the right foot. The results of the research show anthropometric changes in feet of women in the last trimester of pregnancy. They indicate the foot parts in which the greatest changes occur and what the direction of these changes is. This will allow to create a preventive foot corrective exercise program for pregnant women.
\end{abstract}

Key words: lower extremity, foot disorder, pregnant women

\section{Introduction}

Feet provide a foundation for the human body and are intrinsically linked with locomotion, balance, and postural stability. As an important component of the biomechanical chain, changes in foot structure may cause functional limitations or even disorders and are therefore widely studied. During pregnancy, women undergo numerous anatomical, biomechanical, and hormonal changes that may induce various musculoskeletal alterations in the plantar region. The weight gain experienced during pregnancy has been positively correlated with the occurrence of flat feet [1]. This decrease in arch height has been accredited to additional loading on the plantar surface and the shift in the centre of mass towards the rear of the feet to offset the mass of the foetus [2,3]. Other causes include the several-fold rise in the hormone relaxin, which increases joint and ligament laxity and may decrease arch height, as well as the effects of other maternal hormones, including progesterone and oestradiol [3].

Besides changes in plantar structure, volumetric changes in the feet have also been observed and associated with secondary lymphedema in the plantar and calf regions [4]. Other studies have reported similar findings, observing significant pregnancy-related increases in foot volume, as well as foot width and length and a concomitant decrease in longitudinal arch height [5-7]. This transverse expansion of the foot has been attributed to a downward shift of the head of the talus bone in response to weight gained during pregnancy and the effects of relaxin on the metatarsal joint and ankle [5]. Related studies on pregnant women have also reported a reduction in internal arch height [8],

Correspondence address: Katarzyna Barczyk-Pawelec, al. I.J. Paderewskiego 35, 51-612 Wrocław, Poland, e-mail: katarzyna.barczyk-pawelec@awf.wroc.pl

Received: July 22, 2019

Accepted for publication: April 1, 2020

Citation: Barczyk-Pawelec K, Hawrylak A, Bińczyk A, Demczuk-Włodarczyk E. Structural changes in foot and arch dimensions in the third trimester of pregnancy. Hum Mov. 2021;22(2):87-92; doi: https://doi.org/10.5114/hm.2021.100017. 
K. Barczyk-Pawelec A. Hawrylak, A. Bińczyk, E. Demczuk-Włodarczyk, Changes in foot in pregnant women

as well as an increase in plantar pressure [9]. However, one study suggested that the loss of arch height and increase in foot dimensions in pregnant women without articular hypermobility, while common, may be overlooked in the majority of pregnant women, as evidenced by no case studies on this subject in the medical literature [3].

While data on plantar anthropometry and arch structure in young and adult women are well established [10-16], less is known on pregnancy-related changes particularly in the third trimester. The aforementioned anatomical changes, such as the reduction in arch height and associated shift in the centre of mass, can decrease balance control and increase postural instability. To compensate for these adaptations, the spinal curvature can change particularly in the lumbar and cervical regions and cause several spinal pathologies, including back pain and disc herniation [17]. The prevalence of these and other back disorders has been found to increase after 24 weeks of gestation [18]. These postural deviations can also lead to disturbed function of the articular receptors specialized for proprioception, resulting in mechanical overload of the main joints and musculoskeletal pain [17].

The aim of the study was to ascertain the changes in foot anatomy during the final stages of pregnancy. It was hypothesized that foot length and width would increase and arch height would decrease in response to the raised body mass and associated musculoskeletal changes in the third trimester.

\section{Material and methods}

\section{Participants}

The study involved a convenience sample of 20 women under obstetric care at the A. Falkiewicz Specialist Hospital in Wrocław, Poland. The participants' mean age was $30.8 \pm 2.36$ years, height $166.8 \pm 4.57 \mathrm{~cm}$, and body mass $69.1 \pm 5.89 \mathrm{~kg}$. The exclusion criteria and reasons for discontinued participation were prediagnosed pes planus or pes excavatus (prior to pregnancy), loss of pregnancy, and any foot-related injury during the study period. All subjects declared to have had a normal body weight before pregnancy and to have the right leg as the dominant one. Foot structure was assessed at 2 time points: at the beginning of the third trimester of pregnancy $\left(27^{\text {th }}\right.$ week of gestation; Measure I) and at the later stage of the third trimester $\left(37^{\text {th }}-38^{\text {th }}\right.$ week of gestation; Measure II). The participants were informed in detail about the study purpose and methodology.

\section{Procedures}

An imprint of the right and left foot was obtained with a digital podoscope (CQ Elektronik System, Poland). This safe and non-invasive photogrammetric instrument allows for a direct plantar analysis with the use of specialized computer software. The measurements were taken during quiet standing with the arms resting freely against the torso and eyes open and looking forward. The foot image served to compute foot length and width to the nearest $0.5 \mathrm{~mm}$, the foot length to width ratio (FL/FW), and the Sztriter-Godunow index (SGI) as a measure of longitudinal arch height [14]. Angular measures of the feet included the $1^{\text {st }}$ metatarsophalangeal angle (ALPHA) as an indicator of hallux valgus; $5^{\text {th }}$ metatarsophalangeal angle (BETA), which quantifies quintus varus; talocalcaneal angle (GAMMA), used to assess calcaneal valgus; and the Clarke angle (Figure 1). The Clarke angle measures were used to characterize longitudinal arch height, with values ranging $45-50^{\circ}$ indicative of normal arch height, those above $50^{\circ}$ indicative of high arch (pes excavatus), and those below $45^{\circ}$ indicative of collapsed arch (pes planus) [19].

\section{Statistical analysis}

Data were exported for analysis to the Statistica 10.0 software package (StatSoft, USA). The distribution of the tested material was verified with the ShapiroWilk test. Basic descriptive statistics were calculated (mean, standard deviation, and minimum and maximum values) and differences between the repeated measures were analysed by using Student's $t$-test for dependent samples. Statistical significance was adopted at the $p<0.05$ level.

\section{Ethical approval}

The research related to human use has complied with all the relevant national regulations and institutional policies, has followed the tenets of the Declaration of Helsinki, and has been approved by the Ethics Committee of the University School of Physical Education in Wrocław, Poland.

\section{Informed consent}

Informed consent has been obtained from all individuals included in this study. 




1

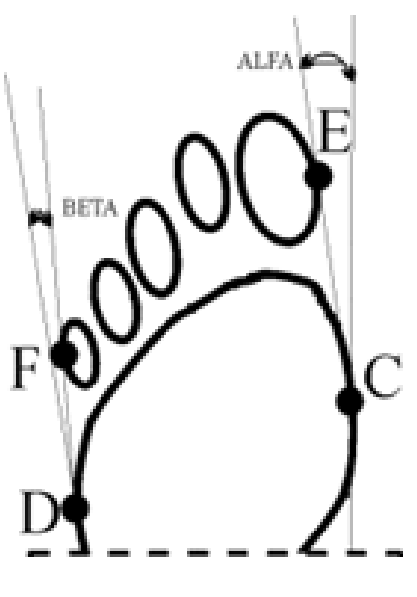

2

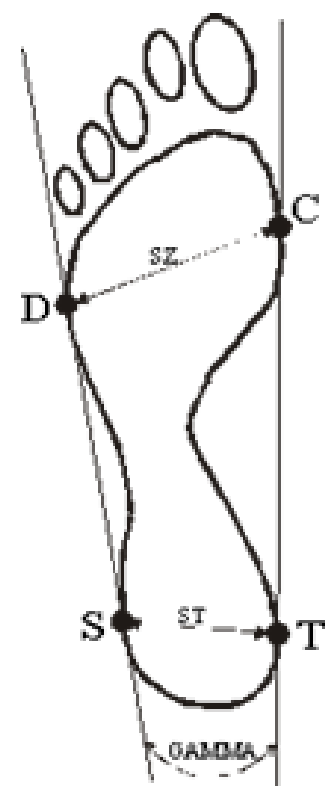

3



4

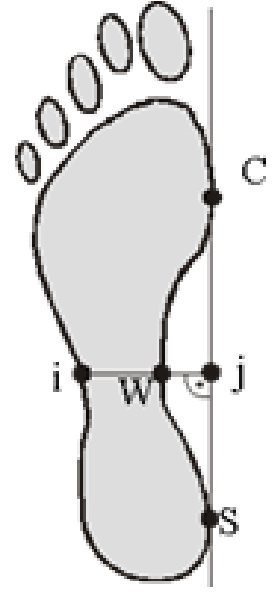

5

1 - foot length as the A-B distance (labelled DL) and foot width as the C-D distance (labelled SZ), $2-1^{\text {st }}$ metatarsophalangeal angle (labelled ALFA) and $5^{\text {th }}$ metatarsophalangeal angle (labelled BETA), 3 - talocalcaneal angle (labelled GAMMA), 4 - Clarke angle (labelled Q), 5 - Sztriter-Godunow index (iW/Wj ratio)

Figure 1. The anthropometric and angular variables measured (source: CQ Elektronik System)

Table 1. Descriptive statistics of body mass at the beginning (Measure I) and end (Measure II) of the third trimester of pregnancy for the study cohort $(n=20)$

\begin{tabular}{|c|c|c|c|c|c|c|c|c|c|c|}
\hline \multirow{2}{*}{ Variable } & \multicolumn{4}{|c|}{ Measure I } & \multicolumn{4}{|c|}{ Measure II } & \multirow{2}{*}{$t$} & \multirow{2}{*}{$p$} \\
\hline & $\bar{x}$ & $S D$ & Min & Max & $\bar{x}$ & $S D$ & Min & Max & & \\
\hline Body mass (kg) & 69.1 & 7.30 & 57.0 & 85.0 & 72.9 & 7.24 & 61.0 & 89.0 & -6.7794 & $<0.001^{*}$ \\
\hline
\end{tabular}

* significant at $p<0.05$

Table 2. Descriptive statistics of foot structure at the beginning (Measure I) and end (Measure II) of the third trimester of pregnancy for the study cohort $(n=20)$

\begin{tabular}{|c|c|c|c|c|c|c|c|c|c|c|c|}
\hline \multirow{2}{*}{ 롤 } & \multirow{2}{*}{ Variable } & \multicolumn{4}{|c|}{ Measure I } & \multicolumn{4}{|c|}{ Measure II } & \multirow{2}{*}{$t$} & \multirow{2}{*}{$p$} \\
\hline & & $\bar{x}$ & $S D$ & Min & Max & $\bar{x}$ & $S D$ & Min & Max & & \\
\hline \multirow{7}{*}{ 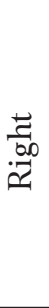 } & $\mathrm{FL}(\mathrm{mm})$ & 232.4 & 8.91 & 220.0 & 253.0 & 233.4 & 8.55 & 221.0 & 251.0 & -1.5599 & 0.1353 \\
\hline & FW (mm) & 89.0 & 4.55 & 83.0 & 97.0 & 90.8 & 4.11 & 83.0 & 97.0 & -1.8670 & 0.0774 \\
\hline & $\mathrm{FL} / \mathrm{FW}$ & 2.6 & 0.14 & 2.3 & 2.8 & 2.6 & 0.16 & 2.4 & 2.9 & 1.5527 & 0.1370 \\
\hline & $\operatorname{ALPHA~}\left(^{\circ}\right)$ & 10.1 & 7.60 & 1.7 & 33.3 & 6.2 & 4.32 & 0.1 & 14.8 & 2.2253 & $0.0384^{*}$ \\
\hline & $\operatorname{BETA}\left(^{\circ}\right)$ & 15.1 & 5.48 & 3.8 & 24.4 & 16.9 & 6.51 & 5.1 & 30.7 & -1.5421 & 0.1396 \\
\hline & GAMMA $\left(^{\circ}\right)$ & 14.2 & 2.60 & 9.6 & 19.2 & 15.4 & 2.51 & 9.6 & 20.5 & -3.0512 & $0.0066^{*}$ \\
\hline & SGI & 0.5 & 0.17 & 0.1 & 0.7 & 0.6 & 0.08 & 0.4 & 0.7 & -3.0822 & $0.0061^{*}$ \\
\hline \multirow{7}{*}{ 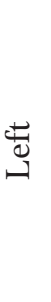 } & FL (mm) & 231.8 & 9.69 & 219.0 & 251.0 & 233.0 & 9.01 & 218.0 & 252.0 & -2.1559 & $0.0441^{*}$ \\
\hline & FW (mm) & 87.3 & 5.20 & 76.0 & 94.0 & 89.7 & 4.71 & 77.0 & 96.0 & -3.6743 & $0.0016^{*}$ \\
\hline & FL/FW & 2.7 & 0.18 & 2.5 & 3.1 & 2.6 & 0.18 & 2.4 & 3.0 & 2.9405 & $0.0084 *$ \\
\hline & $\operatorname{ALPHA~}\left(^{\circ}\right)$ & 7.2 & 5.84 & 1.0 & 22.8 & 8.4 & 5.95 & 1.0 & 22.2 & -1.5030 & 0.1493 \\
\hline & $\operatorname{BETA}\left({ }^{\circ}\right)$ & 16.5 & 6.34 & 2.8 & 25.9 & 17.0 & 6.19 & 1.7 & 25.3 & -0.4134 & 0.6839 \\
\hline & GAMMA $\left(^{\circ}\right)$ & 14.5 & 2.57 & 8.5 & 19.5 & 15.2 & 2.36 & 11.6 & 20.1 & -1.6208 & 0.1215 \\
\hline & SGI & 0.4 & 0.18 & 0.1 & 0.7 & 0.6 & 0.06 & 0.5 & 0.7 & -3.3350 & $0.0035^{*}$ \\
\hline
\end{tabular}

FL - foot length, FW - foot width, ALPHA - $1^{\text {st }}$ metatarsophalangeal angle, BETA $-5^{\text {th }}$ metatarsophalangeal angle, GAMMA - talocalcaneal angle, SGI - Sztriter-Godunow index

* significant at $p<0.05$ 
K. Barczyk-Pawelec A. Hawrylak, A. Bińczyk, E. Demczuk-Włodarczyk, Changes in foot in pregnant women

\section{Results}

Comparisons of body mass between Measure I and Measure II showed a significant increase in mass at the end of the third trimester of pregnancy (Table 1). Several significant changes in the anthropometric and angular measures of the feet were observed although these were different for the right and left foot (Table 2). In the right foot, the ALPHA angle decreased by approximately $1^{\circ}$, whereas the GAMMA angle increased by approximately $1.2^{\circ}$. In the left foot, both foot length and width increased by $1-2 \mathrm{~mm}$, so the FL/FW ratio decreased. For both the right and left foot, SGI increased, although the magnitude difference between Measures I and II was slightly greater for the left foot. The Clarke angle measures revealed that the majority of the cohort presented normal arch height at the beginning and end of the third trimester (Figures 2 and 3 ). The number of participants with a high arch at Measure I decreased at Measure II for the right foot but increased for the left foot. A collapsed arch was present in only 1 woman (right foot) at Measure I and in 1 (left foot) at Measure II.

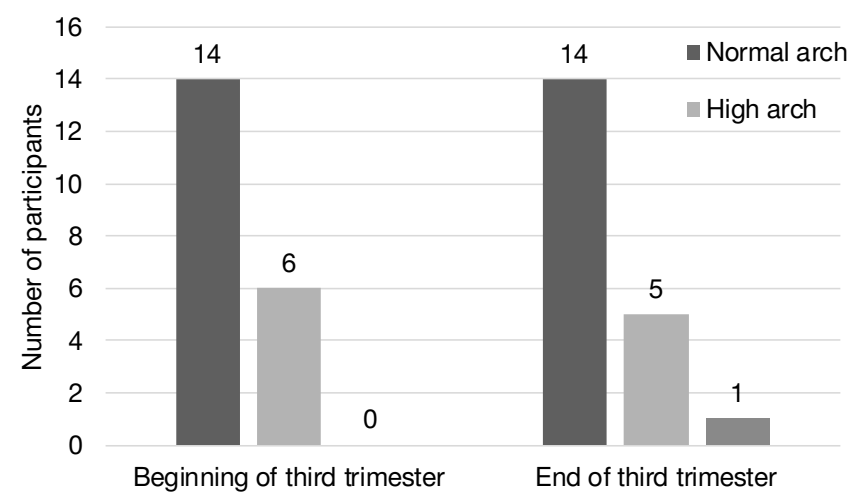

Figure 2. Prevalence of right foot arch structure at the beginning and the end of the third trimester

of pregnancy in the study cohort $(n=20)$



Figure 3. Prevalence of left foot arch structure at the beginning and the end of the third trimester of pregnancy in the study cohort $(n=20)$

\section{Discussion}

Pregnancy induces several physiological adaptations. The weight gained as a result of the growing foetus and increased size of the uterus may anteriorly displace the centre of mass $[20,21]$ and concomitantly shift plantar load from the middle to the rear of the feet $[2,18,22,23]$. Studies have also drawn attention to changes in the anthropometric characteristics of the plantar region as a result of increased body mass and joint and ligament laxity [3]. These effects include an increase in foot length and width, as well as a decrease in the longitudinal and transverse arch heights $[1,20,21]$. While Ciejka et al. [24] attributed the reduction in arch dimensions to biomechanical overloading as a result of the substantial weight gain during pregnancy, they also emphasized the significance of blood circulation in maintaining normal foot shape. The pregnancy-related enlargement of the lymph nodes can impair peripheral blood circulation and cause excess blood retention in the lower extremities. This can perturb muscle metabolism and function, overloading tendon and joint capsule mechanics, and further contribute to a reduction in arch height [25]. This arch drop can induce various compensatory postural changes and be responsible for numerous musculoskeletal disorders $[17,26]$.

The results of the present study also show an increase in foot length and width, although the difference was significant only for the left foot. There was also a concurrent decrease in the FL/FW ratio for the left foot. However, it is worth noting that there was a greater range between minimum and maximum values for the right foot. Presumably, an explanation for the lack of congruity between the right and left foot may be a result of lower extremity dominance. These results confirm, in part, the findings of several studies which observed pregnancy-related changes in the shape and size of feet, such as a significant increase in foot length, width, and volume and a slight decrease in foot height in a group of 40 women measured across 3 time points during their pregnancy [5]. Another study also substantiated the anthropometric effects of pregnancy on foot structure, although the increases in foot length and width were concentrated in the forefoot region and relatively moderate [8]. One study found no significant changes in either foot length or width during the course of pregnancy, although foot volume did significantly fluctuate [25]. This was attributed to the retention of extracellular fluid or accumulation of soft tissue in the feet. One study suggested that the pregnancy-related structural changes in the feet may be permanent, 
as evidenced by lower arch height and rigidity indexes measured 19 weeks postpartum, and may lead to subsequent musculoskeletal disorders [3]. This was observed alongside a concomitant increase in foot length and width in approximately $60-70 \%$ of the sample [3].

The present results on the angular characteristics of the feet revealed only minor differences between the measures taken at the beginning and end of the third trimester of pregnancy. Longitudinal arch height decreased in the last trimester of pregnancy, as evidenced by an increase in SGI in both the right and left foot. However, the increase in the GAMMA angle alongside this index was statistically significant only in the right foot. The prevalence of arch structure types as ascertained by the Clarke angle demonstrated the presence of both normal and abnormal arch structure at both the beginning and end of the third trimester of pregnancy. The increase in mean Clarke angle was significant in the left foot. While the increase in the BETA angle was only slightly higher between the 2 time points and not significant, greater variability was observed in the individual results as evidenced by the greater spread of the maximum and minimum values and larger standard deviations. In the case of hallux valgus, as ascertained by the ALPHA angle, the significant although minor changes could have been a result of the relatively small sample size.

\section{Limitations}

The present study has several limitations that require acknowledgement. First, body mass prior to pregnancy was not measured, and its determination would have provided a better perspective on the tangible increase in body mass in the third trimester. However, all participants indicated that their pre-pregnancy body mass had been within norms. Another limitation was that arch structure was not assessed before pregnancy and during its early stages, warranting the need for additional research on foot anatomy. Finally, the study did not evaluate the prevalence of foot or back pain and its intensity and frequency. Future research on these issues should assess the entire period of pregnancy, identify the prevalence of pregnancy-related musculoskeletal problems, and determine if any preventive strategies can be developed to mitigate the pregnancy-related changes in foot structure.

\section{Conclusions}

The study confirmed several changes in plantar and arch structure during the third trimester of pregnancy, primarily an increase in the length and width of the left foot and alterations in some angular characteristics of the right foot. Arch height also decreased in both the right and left foot. Considering the relationship between the feet and upper body musculoskeletal health, future studies should further examine the effects of plantar and arch structure on posture and the prevalence of low back pain. Such investigation could aid the development of a holistic approach towards alleviating many pregnancy-related conditions, including mechanical overloading, musculoskeletal pain, or lowered quality of life due to discomfort.

\section{Disclosure statement}

No author has any financial interest or received any financial benefit from this research.

\section{Conflict of interest}

The authors state no conflict of interest.

\section{References}

1. Lizis P. The relationship between the shape of plantar surface of feet and body build features in females. Fizjoter Pol. 2011;11(1):57-65.

2. Nyska M, Sofer D, Porat A, Howard CB, Levi A, Meizner I. Planter foot pressures in pregnant women. Isr J Med Sci. 1997;33(2):139-146.

3. Segal NA, Boyer ER, Teran-Yengle P, Glass NA, Hillstrom HJ, Yack HY. Pregnancy leads to lasting changes in foot structure. Am J Phys Med Rehabil. 2013;92(3): 232-240; doi: 10.1097/PHM.0b013e31827443a9.

4. Dunn J, Dunn C, Habbu R, Bohay D, Anderson J. Effect of pregnancy and obesity on arch of foot. Orthop Surg. 2012;4(2):101-104; doi: 10.1111/j.1757-7861.2012.00 179.x.

5. Wetz HH, Hentschel J, Drerup B, Kiesel L, Osada N, Veltmann U. Changes in shape and size of the foot during pregnancy[inGerman].Orthopade.2006;35(11):11241130; doi: 10.1007/s00132-006-1011-1.

6. Hadasik D, Repeć R, Zaniewski M. Chronic venous insufficiency in pregnant women - primum non nocere. Review [in Polish]. Ginekol Położ. 2007;3(5):63-71.

7. Krasowski G, Rybak Z, Niemczyk W, Tukiendorf A, Kornacki W. Effect of body mass gain during pregnancy on the venous system function in lower limbs [in Polish]. Przegl Flebol. 2007;15(1):1-4.

8. Gijon-Nogueron GA, Gavilan-Diaz M, Valle-Funes V, Jimenez-Cebrian AM, Cervera-Marin JA, MoralesAsencio JM. Anthropometric foot changes during pregnancy: a pilot study. J Am Podiatr Med Assoc. 2013; 103(4):314-321; doi: 10.7547/1030314.

9. Gaymer C, Whalley H, Achten J, Vatish M, Costa ML. Midfoot plantar pressure significantly increases during late gestation. Foot. 2009;19(2):114-116; doi: 10.1016/ j.foot.2009.02.001. 


\section{HUMAN MOVEMENT}

K. Barczyk-Pawelec A. Hawrylak, A. Bińczyk, E. Demczuk-Włodarczyk, Changes in foot in pregnant women

10. Bibrowicz K, Osińska M, Chodun M. Foot arch asymmetry in women aged 20-40 years with normal body mass under weight loading conditions, in the perspective of digital photopodoscopy examinations [in Polish]. Med Man. 2012;16(1):24-30.

11. Nogalski S, Salaciak A. Plantar structure comparison among University of Szczecin female students with the consideration of body build [in Polish]. Zesz Nauk USzczec. 1992;9:119-132.

12. Puszczałowska-Lizis E. Correlations between the plantographic characteristics of feet and the explosive power of the lower limbs in 20-27 years old women. Fizjoterapia. 2011;19(2):9-15; doi: 10.2478/v10109-011-0001-y.

13. Puszczałowska-Lizis E. Verification of the correctness in index choice in foot structure evaluation on the basis of research into the feet of women aged 20 to 27 . Med Rehab. 2011;15(2):1-6.

14. Puszczałowska-Lizis E. Connections between the longitudinal arch of the foot and the chosen morphological features of the body in 20-27 years women. Prz Med Uniw Rzesz Inst Leków. 2012;1:50-57.

15. Puszczałowska-Lizis E. Index of slenderness vs. longitudinal arch of students' feet [in Polish]. Hyg Publ Health. 2014;49(1):98-102.

16. Karadag-Saygi E, Unlu-Ozkan F, Basgul A. Plantar pressure and foot pain in the last trimester of pregnancy. Foot Ankle Int. 2010;31(2):153-157; doi: 10.3113/FAI. 2010.0153.

17. Niedzielski W, Śliwiński Z, Permoda A. Influence of transverse flat-foot on the disturbance of natural physiological position [in Polish]. Med Man. 2014;18(1):37-41.

18. Majchrzycki M, Mrozikiewicz PM, Kocur P, Bartkowiak-Wieczorek J, Hoffmann M, Stryła W, et al. Low back pain in pregnant women [in Polish]. Ginekol Pol. 2010;81(11):851-855.

19. Kutzner-Kozińska M, Olszewska E, Popiel M, Trzcińska D. The process of correcting postural defects [in Polish]. Warszawa: AWF; 2011.

20. Boch-Kmieciak J, Cieślik K, Waszak M, Szulc P, Lewandowski J. Changes in somatic features and spinal curvatures in pregnant women. Fizjoter Pol. 2012;12(4): 29-38; doi: 10.5604/16420136.990855.

21. Estemberg D, Sikora-Szubert A, Kowalska-Koprek U, Berner-Trąbska M, Brzozowska M, Pasiński J, et al. Body mass changes during pregnancy and concentration of insulin and neuropeptide $\mathrm{Y}$ in women with regard to the BMI [in Polish]. Ginekol Pol. 2011;82(12):892-899.

22. Murphy DR, Hurwitz EL, McGovern EE. Outcome of pregnancy-related lumbopelvic pain treated according to a diagnosis-based decision rule: a prospective observational cohort study. J Manipulative Physiol Ther. 2009;32(8):616-624;doi:10.1016/j.jmpt.2009.09.002.

23. Robinson HS, Mengshoel AM, Bjelland EK, Vøllestad NK. Pelvic girdle pain, clinical tests and disability in late pregnancy. Man Ther. 2010;15(3):280-285; doi: 10.1016/j.math.2010.01.006.
24. Ciejka E, Daniszewska B, Janiszewski M. Pathological changes in plantar arch structure in adults induced by overload syndromes [in Polish]. Med Man. 2001;3-4: 35-38.

25. Alvarez R, Stokes IA, Asprinio DE, Trevino S, Braun T. Dimensional changes of the feet in pregnancy. J Bone Joint Surg Am. 1988;70(2):271-274.

26. Menz HB, Dufour AB, Riskowski JL, Hillstrom HJ, Hannan MT. Foot posture, foot function and low back pain: the Framingham Foot Study. J Foot Ankle Res. 2013; 6(Suppl. 1):O27; doi: 10.1186/1757-1146-6-S1-O27. 